\title{
An HPLC-PDA Method for Determination of Alectinib Concentrations in the Plasma of an Adolescent
}

\author{
Samiuela Lee ${ }^{1}$, Christa E. Nath ${ }^{1,2^{*}}$, Ben W. R. Balzer ${ }^{3,4}$, Craig R. Lewis ${ }^{5,6}$, Toby N. Trahair ${ }^{4,7}$, \\ Antoinette C. Anazodo ${ }^{4,5,7}$ and Peter J. Shaw ${ }^{8,9}$ \\ 'Department of Biochemistry, The Children's Hospital at Westmead, Australia \\ Faculty of Pharmacy, University of Sydney, Australia \\ ${ }^{3}$ Sydney Children's Hospital, Randwick NSW 2031, Australia \\ 'School of Women's and Children's Health, University of New South Wales, Randwick NSW 2031, Australia \\ ${ }^{5}$ Nelune Comprehensive Cancer Centre, Prince of Wales Hospital, Randwick NSW 2031, Australia \\ ${ }^{6}$ Prince of Wales Clinical School, University of New South Wales, Randwick NSW 2031, Australia \\ Kids Cancer Centre, Sydney Children's Hospital, Randwick NSW 2031, Australia \\ ${ }^{8}$ Cancer Centre for Children, The Children's Hospital at Westmead, Australia \\ Discipline of Child and Adolescent Health, University of Sydney, Australia
}

Received: 03 Dec 2018; accepted: 03 Aug 2019

\begin{abstract}
Alectinib is a central nervous system-active small molecule anaplastic lymphoma kinase (ALK) inhibitor that is effective in the treatment of patients with ALK positive tumors, including advanced non-small cell lung cancers and lymphomas. A simple, isocratic high-performance liquid chromatography-photo diode array detection (HPLCPDA) assay for measurement of alectinib in human plasma is described. Alectinib is extracted from the plasma matrix by addition of methanol, followed by centrifugation and acidification with $0.1 \%$ formic acid. It elutes with a run time of $4.6 \mathrm{~min}$ using a $250 \mathrm{~mm} \times 4.6 \mathrm{~mm}$ RP-C18 column with $0.1 \%$ aqueous formic acid and methanol $(35: 65, v / v)$ and a flow rate of $1 \mathrm{~mL} / \mathrm{min}$. Detection was at $339 \mathrm{~nm}$. Linear calibration plots were achieved in the range of $0.1-20 \mu \mathrm{g} / \mathrm{mL}$ for alectinib $\left(r^{2}=0.9996\right)$. With limits of detection and quantification of 0.05 and $0.1 \mu \mathrm{g} /$ $\mathrm{mL}$, respectively, and excellent precision $(\% \mathrm{CV}<10 \%)$, accuracy (bias $< \pm 12 \%)$, and recovery $(>97 \%)$ within the $1-20 \mu \mathrm{g} / \mathrm{mL}$ concentration range, this assay was suitable for measuring pre-dose alectinib concentrations in an adolescent receiving 600-mg doses twice daily.
\end{abstract}

Keywords: HPLC-PDA, alectinib, human plasma

\section{Introduction}

Alectinib (9-ethyl-6,6-dimethyl-8-[4-(morpholin-4-yl)piperidin-1-yl]-11-oxo-6,11-dihydro-5H-benzo[b]carbazole-3-carbonitrile hydrochloride, Figure 1) is a highly selective, small molecule ALK inhibitor that is effective in the treatment of patients with advanced ALK-positive tumors, including nonsmall-cell lung cancers and lymphomas. This drug is also effective in patients with central nervous system disease $[1,2]$. In a phase $1 / 2$ study, dose proportionality with respect to maximal plasma concentrations and area under the plasma concentration-time curve was demonstrated across a dose range of 300 to $900 \mathrm{mg}$ twice daily, with $600-\mathrm{mg}$ twice daily being recommended for further phase 2 studies on the basis of activity, tolerability, and pharmacokinetics [2]. In this study, higher steady-state trough concentration was associated with greater reductions in tumor size; a plateau was reached corresponding to the $600 \mathrm{mg}$ twice-daily dose. This dose was later confirmed in a population pharmacokinetic analysis [3] and in a recent exposure-response analysis that was conducted in 225 adults with ALK-positive non-small-cell lung cancer in which

\footnotetext{
* Author for correspondence: Department of Biochemistry, The Children's Hospital at Westmead, Locked Bag 4001, Westmead, NSW, 2145, Australia; Tel: 612 98453287; Fax: 612 98453332; E-mail: christa.nath@health.nsw. gov.au.
}

steady-state trough concentration was used as the clinically relevant and practical measure of exposure [4]. Alectinib concentration monitoring and pharmacokinetic assessment have not previously been performed in children or adolescents. Previously published methods for determination of alectinib in human plasma to date have utilized expensive liquid chromatography-mass spectrometry (LC-MS) equipment, and some employ deuterated internal standards $[5,6]$. The aim of this study was to develop and validate a sensitive, simple, and inexpensive method to enable alectinib concentration monitoring and pharmacokinetic assessment in patients.

\section{Experimental}

Chemicals and Reagents. Alectinib (Alecensa ${ }^{\circledR}, 600 \mathrm{mg}$ ) pharmaceutical preparation was purchased from Genentech (CA, USA). High-performance liquid chromatography (HPLC)-grade acetonitrile and methanol were obtained from Bio-Strategy Laboratory Supplies (Sydney, Australia). All other chemicals and solvents used were of analytical grade. Distilled water from distillation apparatus (Millipore, Sydney Australia) was used in all aqueous solutions.

Preparation of Stock Solutions of the Standards and Quality Control Samples. A stock solution of alectinib $(1 \mathrm{mg} / \mathrm{mL})$ was prepared with $2.0 \mathrm{~mL}$ methanol and diluted to make working solutions. Alectinib standards $(0.1,0.25,0.5$,

This is an open-access article distributed under the terms of the Creative Commons Attribution-NonCommercial 4.0 International License (https://creativecommons.org/licenses/by-nc/4.0/), which permits unrestricted use, distribution, and reproduction in any medium for non-commercial purposes, provided the original author and source are credited, a link to the CC License is provided, and changes - if any - are indicated. 


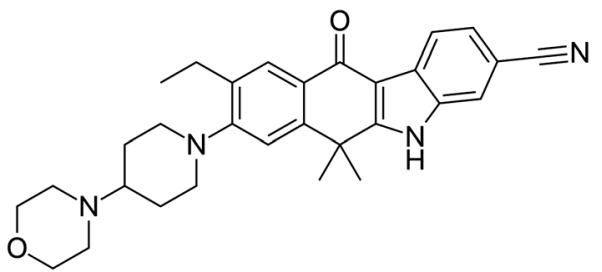

Figure 1. Chemical structure of alectinib

$0.75,1.0,2.5,5,10$, and $20 \mu \mathrm{g} / \mathrm{mL})$ were prepared in drugfree human plasma. Quality control (QC) samples $(0.1,1,10$, $20 \mu \mathrm{g} / \mathrm{mL}$ ) were independently prepared in the same manner. All stock and working solutions of standards and QC samples were stored at $-40{ }^{\circ} \mathrm{C}$ until analysis.

Sample Preparation Procedure. An aliquot $(100 \mu \mathrm{L})$ of standard, QC or patient plasma sample was transferred into a $1.5-\mathrm{mL}$ microcentrifuge tube and precipitated with methanol $(200 \mu \mathrm{L})$. The mixture was vortexed for $30 \mathrm{~s}$ and then centrifuged for $7 \mathrm{~min}$ at $13,400 \mathrm{~g}$ in an Eppendorf Minispin centrifuge. A $200 \mu \mathrm{L}$ aliquot of the supernatant was mixed with $100 \mu \mathrm{L}$ of $0.1 \%$ aqueous formic acid in a $250-\mu \mathrm{L}$ glass insert in a $2-m L$ HPLC vial. Fifty microliters of the contents was injected into the HPLC system.

Instrumentation and Chromatographic Conditions. HPLC analyses were carried out on a Shimadzu Nexera UHPLC system comprising of a solvent delivery system of 2 pumps (LC-30 AD), an autoinjector (SIL-30 AC Auto Sampler), and a photo diode array (PDA) detector (SPDM30A). Data collection and integration were accomplished using Shimadzu Labsolutions software. The wavelength of detection was at $339 \mathrm{~nm}$. Separation of analytes was performed using an Alltech Apollo $4.6 \mathrm{~mm} \times 250 \mathrm{~mm}, 5-\mu \mathrm{m}$ RP-C18 column, preceded by a Brownlee pre-column $1.5 \mathrm{~cm} \times 3.2 \mathrm{~mm}, 7-\mu \mathrm{m}, \mathrm{RP}-\mathrm{C} 18$ (Grace Davison Discoveries Sciences Pty Ltd., Epping, VIC, Australia). The mobile phase was composed of $0.1 \%$ aqueous formic acid in solvent $\mathrm{A}$ and methanol in solvent $\mathrm{B}$ in an isocratic composition of $35: 65$, respectively. This mobile phase composition provided the highest detection sensitivity, good peak symmetry, and good separation from other compounds in plasma. The mixture was mixed well and was filtered to degas prior to analysis.

Method Validation. Inter-day precision and accuracy for alectinib were determined by analyzing 10 QC samples on different days. Precision was characterized by the coefficients of variation $(\% \mathrm{CV})$ whereas accuracy was expressed as a relative difference between the measured and the nominal value. The recovery of alectinib was determined by taking the peak area of the spiked plasma standards as a percentage of the peak area of the spiked methanol standards. The recovery concentration levels tested were $0.1,1,10$, and $20 \mu \mathrm{g} / \mathrm{mL}$, with 3 replicates per level (mean and standard deviation [SD] were reported). The linearity of the assay response was assessed by obtaining peak area values for alectinib plasma standards over the concentration range $0.1-20 \mu \mathrm{g} / \mathrm{mL}$ and obtaining the equation and coefficient of determination $\left(r^{2}\right)$ of the least squares regression line. The limit of quantification (LOQ) is the lowest amount of alectinib in a sample that can be quantitatively determined with suitable precision and accuracy and was estimated as 10 times the signal-to-noise (S/ $\mathrm{N})$ ratio, while the limit of detection (LOD) was calculated using an $\mathrm{S} / \mathrm{N}$ value of 3 . Specificity of the method was tested with respect to samples retrieved from 6 oncology patients who did not receive alectinib, to determine whether there was interference from the matrices. Stability experiments were conducted in triplicate to evaluate the short-term stability (\% recovery of plasma QC samples after storage at room temperature for 1,4 , and $24 \mathrm{~h})$, mid-length stability (\% recovery of plasma QC samples after storage at room temperature for 7 days), long-term stability ( $\%$ recovery of plasma QC samples after storage at $-40{ }^{\circ} \mathrm{C}$ for 30 days), and autosampler stability (\% recovery of alectinib from methanolic extracts after 1,4 , and $24 \mathrm{~h}$ ).

Concentration Determination in a Patient. The method was used to measure alectinib concentrations in an adolescent with stage IV lung adenocarcinoma treated with oral alectinib capsules twice daily (Alecensa ${ }^{\circledR}, 600 \mathrm{mg}$ ). Lithium heparin blood samples $(1-2 \mathrm{~mL})$ were collected prior to the first alectinib dose, then at $0 \mathrm{~min}, 0.5 \mathrm{~h}, 1 \mathrm{~h}, 2 \mathrm{~h}, 4 \mathrm{~h}, 6 \mathrm{~h}, 12 \mathrm{~h}$, and $24 \mathrm{~h}$ after the first dose, and then immediately prior to the dose on days 8,15 , and 21 of treatment. Plasma samples were separated by centrifugation at $13,400 \mathrm{rpm}$ for $5 \mathrm{~min}$ at room temperature. All samples were stored at $-40{ }^{\circ} \mathrm{C}$ until analysis. The pre-dose sample, alectinib-free, allowed the determination of the specificity of the assay. Ethics approval, informed guardian consent, and patient assent were obtained to collect blood samples and measure alectinib concentrations in these patients.

\section{Results and Discussion}

Using the optimized chromatographic conditions, alectinib eluted with a retention time of $4.6 \mathrm{~min}$. Representative chromatograms of a spiked plasma standard containing $5 \mu \mathrm{g} / \mathrm{mL}$ alectinib and a patient sample containing $0.88 \mu \mathrm{g} / \mathrm{mL}$ alectinib are shown in Figures $2 \mathrm{~A}$ and $2 \mathrm{~B}$, respectively. No endogenous components were observed to co-elute with the peak in the pre-dose plasma sample (Figure 2C) or in the plasma samples from 6 oncology patients who did not receive alectinib. Linear regression of the peak area ratios versus concentration $(\mu \mathrm{g} /$ $\mathrm{mL}$ ) in the $0.1-20 \mu \mathrm{g} / \mathrm{mL}$ concentration range yielded a regression equation of $y=35,660 x-3584$, where $y$ is the alectinib concentration $(\mu \mathrm{g} / \mathrm{mL})$ and $x$ is the peak area; the regression coefficient $\left(r^{2}\right)$ was 0.9996 . The LOD was $0.05 \mu \mathrm{g} /$ $\mathrm{mL}$, and the LOQ was $0.1 \mu \mathrm{g} / \mathrm{mL}(\% \mathrm{CV}$ : $15 \%)$. Previously published liquid chromatographic-mass spectrometry methods had lower limits of detection and quantification between 1 and $5 \mathrm{ng} / \mathrm{mL}[5,6]$.

The inter-day accuracy and precision of the alectinib assay are summarized in Table 1, and recovery results are summarized in Table 2. The inter-day precision and accuracy were < $\pm 12 \%$ for concentrations ranging from 1 to $20 \mu \mathrm{g} / \mathrm{mL}$, while the precision and bias for the LOQ of $0.1 \mu \mathrm{g} / \mathrm{mL}$ concentration were $<15 \%$. These are within the acceptable limits of performance, according to the European Medicines Agency Guidelines, which states that precision and bias should be within $\pm 15 \%$ for all quality control samples except the LOQ, which should be within $\pm 20 \%$ [7]. Recovery from plasma was also excellent (97.3-108.6\%), indicating a minimal matrix effect.

Consistent with the previously published methods $[5,6]$, alectinib was found to be stable in plasma after storage at $-40{ }^{\circ} \mathrm{C}$ for 3 months and at room temperature for up to a week (there was $<5 \%$ degradation). There was also minimal degradation $(<2 \%)$ of the sample extracts stored in the autosampler at room temperature for $24 \mathrm{~h}$.

Table 3 shows the alectinib concentrations measured in an adolescent over the first 21 days of treatment. After administration of the first dose, concentrations were first detected in the plasma at 6 -h postdose. Pre-dose concentrations were at steady state after approximately 8 days of treatment. No peaks were observed in the pre-dose sample, indicating adequate specificity. After twice-daily 600-mg dosing, the adolescent achieved equivalent alectinib steady-state trough 

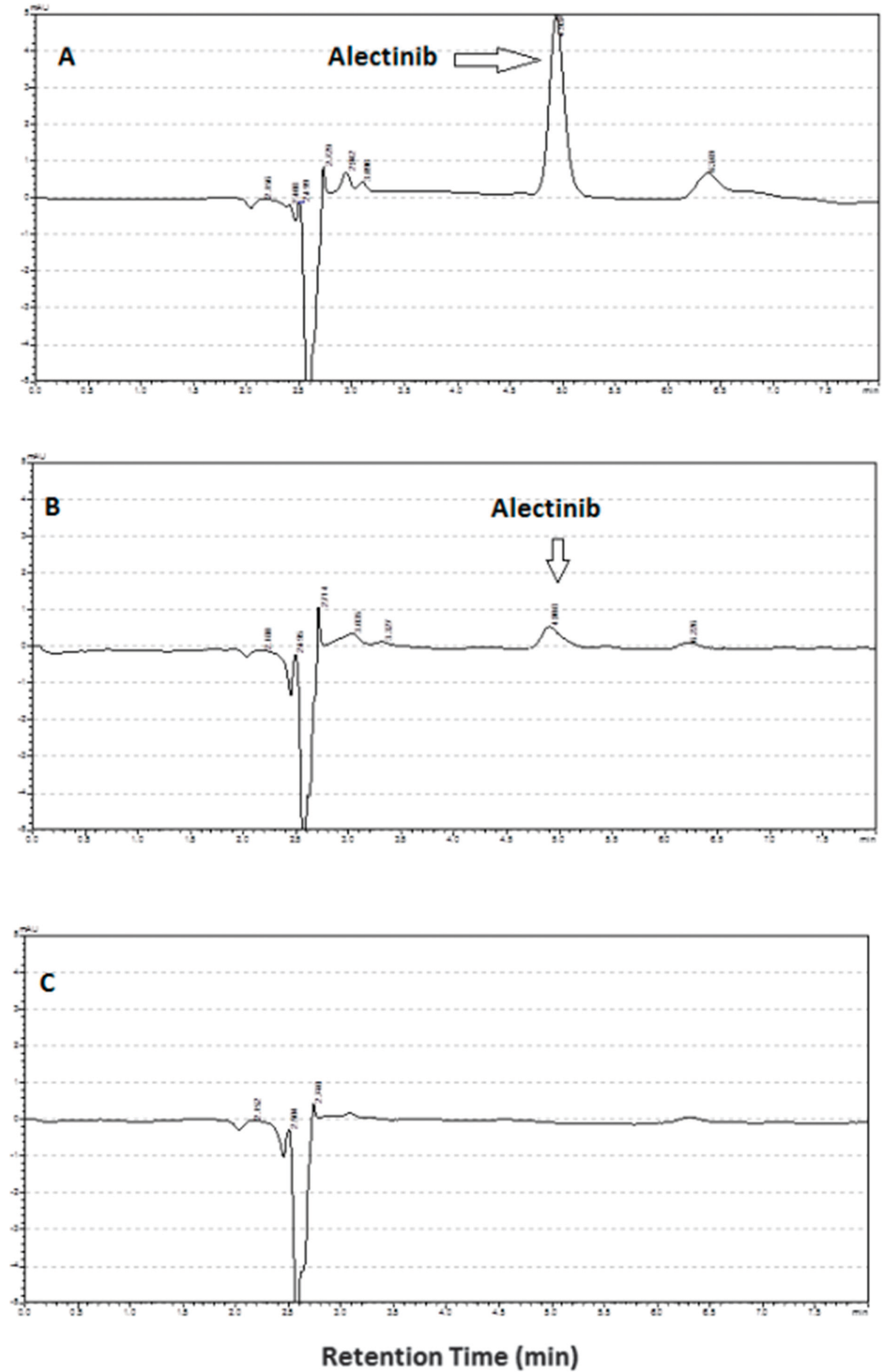

Figure 2. Representative chromatograms of a spiked plasma standard containing $5 \mu \mathrm{g} / \mathrm{mL}$ alectinib (A), a patient sample containing $0.88 \mu \mathrm{g} / \mathrm{mL}$ alectinib (B), and a pre-dose plasma sample with no alectinib (C) 
Table 1. Inter-day precision and accuracy for alectinib of quality control samples in human plasma $(n=10)$

\begin{tabular}{lcccc}
\hline & \multicolumn{4}{c}{ Nominal alectinib concentration } \\
\cline { 2 - 5 } & $0.1 \mu \mathrm{g} / \mathrm{mL}$ & $1 \mu \mathrm{g} / \mathrm{mL}$ & $10 \mu \mathrm{g} / \mathrm{mL}$ & $20 \mu \mathrm{g} / \mathrm{mL}$ \\
\hline Measured alectinib & 0.08 & 0.93 & 11.67 & 22.79 \\
concentrations & 0.08 & 0.87 & 10.72 & 20.63 \\
$(\mu \mathrm{g} / \mathrm{mL})$ & 0.08 & 0.95 & 11.62 & 21.79 \\
& 0.07 & 0.87 & 11.24 & 21.15 \\
& 0.08 & 0.93 & 10.78 & 21.57 \\
& 0.09 & 0.99 & 11.56 & 23.50 \\
& 0.09 & 0.85 & 11.47 & 22.67 \\
& 0.11 & 1.07 & 10.63 & 22.90 \\
& 0.09 & 0.96 & 11.33 & 22.55 \\
Mean & 0.08 & 1.12 & 11.11 & 22.90 \\
SD & $\mathbf{0 . 0 9}$ & $\mathbf{0 . 9 5}$ & $\mathbf{1 1 . 2 1}$ & $\mathbf{2 2 . 2 5}$ \\
\%CV & $\mathbf{0 . 0 1}$ & $\mathbf{0 . 0 9}$ & $\mathbf{0 . 3 9}$ & $\mathbf{0 . 9 1}$ \\
\%bias & $\mathbf{1 4 . 7 5}$ & $\mathbf{9 . 1 2}$ & $\mathbf{3 . 4 7}$ & $\mathbf{4 . 0 9}$ \\
& $\mathbf{- 1 4 . 3 3}$ & $\mathbf{- 4 . 6 4}$ & $\mathbf{1 2 . 1 2}$ & $\mathbf{1 1 . 2 3}$ \\
\hline
\end{tabular}

Table 2. Recovery of alectinib after methanol precipitation

\begin{tabular}{lcccc}
\hline & \multicolumn{4}{c}{ Nominal alectinib concentration } \\
\cline { 2 - 5 } & $0.1 \mu \mathrm{g} / \mathrm{mL}$ & $1 \mu \mathrm{g} / \mathrm{mL}$ & $10 \mu \mathrm{g} / \mathrm{mL}$ & $20 \mu \mathrm{g} / \mathrm{mL}$ \\
\hline \% Recovery & 108.6 & 100.2 & 100.4 & 100.8 \\
& 106.0 & 101.0 & 97.3 & 99.6 \\
& 107.4 & 98.5 & 102.5 & 99.5 \\
Mean & $\mathbf{1 0 7 . 3 3}$ & $\mathbf{9 9 . 9 0}$ & $\mathbf{1 0 0 . 0 7}$ & $\mathbf{9 9 . 9 7}$ \\
SD & $\mathbf{1 . 3 0}$ & $\mathbf{1 . 2 8}$ & $\mathbf{2 . 6 2}$ & $\mathbf{0 . 7 2}$ \\
\hline
\end{tabular}

concentrations to that previously reported in 207 adults, where the mean $\pm \mathrm{SD}$ of the active concentrations (represented as the sum of the alectinib + M4 metabolite) were $1.68 \pm 0.45 \mu \mathrm{M}$ [4]. The M4 metabolite, which was not measured in this study, can be expected to contribute an additional 10\% (approximately) of active concentration units to the analytical sample [8]. Alectinib is usually used to treat adult cancers, and there is little previously published alectinib dosing or concentration data in pediatric or adolescent patients.

\section{Conclusions}

The method described in this manuscript has been developed and validated over the concentration range of $0.1-$ $20.0 \mu \mathrm{g} / \mathrm{mL}$ in human plasma. While not as sensitive as liquid chromatographic-mass spectrometry methods this HPLCPDA method utilizes inexpensive equipment and is simple and fast to perform, with a rapid protein precipitation extraction and a chromatographic run time of $4.6 \mathrm{~min}$. The method
Table 3. Measured alectinib concentrations in an adolescent $(57.3 \mathrm{~kg})$ who had 600-mg oral doses twice daily

\begin{tabular}{lcccc}
\hline $\begin{array}{l}\text { Day } \\
\text { of } \\
\text { treatment }\end{array}$ & $\begin{array}{c}\text { Alectinib } \\
\text { dose } \\
\text { number }\end{array}$ & $\begin{array}{c}\text { Time } \\
\text { after dose } \\
(\mathrm{h})\end{array}$ & $\begin{array}{c}\text { Alectinib } \\
\text { concentration } \\
(\mu \mathrm{g} / \mathrm{mL})\end{array}$ & $\begin{array}{c}\text { Alectinib } \\
\text { concentration } \\
(\mu \mathrm{M})\end{array}$ \\
\hline 1 & 1 & 0 & 0 & 0 \\
& & 0.5 & 0 & 0 \\
& & 1 & 0 & 0 \\
& & 2 & 0 & 0 \\
1 & & 4 & 0 & 0 \\
1 & 1 & 12 & 0.01 & 0.02 \\
8 & 2 & 12 & 0.18 & 0.38 \\
15 & 16 & 12 & 0.37 & 0.77 \\
21 & 30 & 12 & 1.02 & 1.7 \\
\hline
\end{tabular}

was successfully applied to monitor pre-dose alectinib concentrations in an adolescent being treated with Alecensa ${ }^{\circledR}$ capsules.

Acknowledgements. S.L. was supported by the Kids Cancer Alliance (KCA), a CINSW Translational Cancer Research Centre (15/TRC/1-04). C.E.N. is supported by the Leukaemia Research Support Fund of The Children's Hospital Westmead. Funding for the Shimadzu Nexera U-HPLC was obtained from a NSW Cancer Institute Equipment Grant (14/ REG/1-03).

\section{References}

1. Camidge, P. S.; Shaw, A. T.; Gadgeel, S.; Ahn, J. S.; Kim, D. W.; Ou, S. I.; Pérol, M.; Dziadziuszko, R.; Rosell, R.; Zeaiter, A.; Mitry, E.; Golding, S.; Balas, B.; Noe, J.; Morcos, P. N.; Mok, T. N. Engl. J. Med. 2017, 377, 829.

2. Gadgeel, S. M.; Gandhi, L.; Riely, G. J.; Chiappori, A. A.; West, H. L.; Azada, M. C.; Morcos, P. N.; Lee, R.; Garcia, L.; Yu, L.; Boisserie, F.; Di Laurenzio, L.; Golding, S.; Sato, J.; Yokoyama, S.; Tanaka, T.; Ou, S. I. Lancet 2014, 15, 1119 .

3. Hsu, J. C.; Carnac, R.; Henschel, V.; Bogman, K.; Martin-Facklam, M.; Guerini, E.; Balas, B.; Zeaiter, A. H.; Phipps, A.; Morcos, P. N.; Frey, N. J. Clin. Oncol. 2016, 34, abstract e20598.

4. Morcos, P. N.; Nueesch, E.; Jaminion, F.; Guerini, E.; Hsu, J. C.; Bordogna, W.; Balas, B.; Mercier, F. Cancer Chemother. Pharmacol. 2018, 82, 129.

5. Huang, X.-X.; Li, Y.-X.; Li, X.-Y.; Hu, X.-X.; Tang, P.-F.; Hu, G.-X. J. Pharm. Biomed. Anal. 2017, 132, 227.

6. Srikanth, I.; Prameela, R. A. Int. J. Curr. Res. 2017, 9, 51506.

7. European Medicines Agency. Guideline on Bioanalytical Method Validation. http://www.ema.europa.eu/docs/en_GB/document_library/Scientific_guideline/ 2011/08/WC500109686.pdf (Accessed: October 2018)

8. Sato-Nakai, M.; Kawashima, K.; Nakagawa, T.; Tachibana, Y.; Yoshida, M.; Takanashi, K.; Morcos, P. N.; Binder, M.; Moore, D. J.; Yu, L. Heliyon 2017, 3, e00354. 